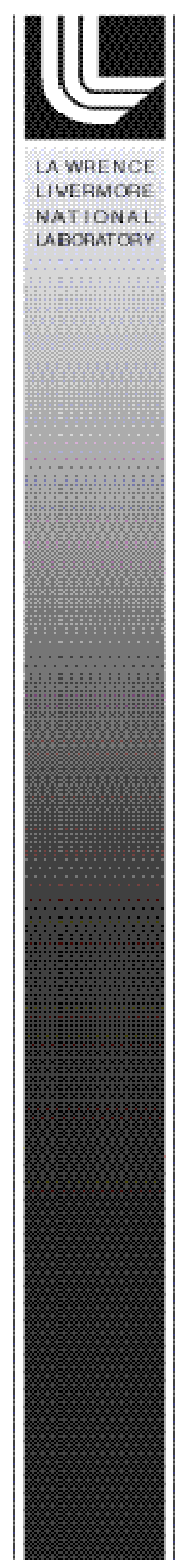

\title{
High-Energy Neutron Imaging Development at LLNL
}

J. M. Hall (PI), B. Rusnak and P. J. Fitsos

Lawrence Livermore National Laboratory

6 December 2006

FY06 Annual Report submitted for ESC project LL-24 


\section{Disclaimer}

This document was prepared as an account of work sponsored by an agency of the United States Government. Neither the United States Government nor the University of California nor any of their employees, makes any warranty, express or implied, or assumes any legal liability or responsibility for the accuracy, completeness, or usefulness of any information, apparatus, product, or process disclosed, or represents that its use would not infringe privately owned rights. Reference herein to any specific commercial product, process, or service by trade name, trademark, manufacturer, or otherwise, does not necessarily constitute or imply its endorsement, recommendation, or favoring by the United States Government or the University of California. The views and opinions of authors expressed herein do not necessarily state or reflect those of the United States Government or the University of California, and shall not be used for advertising or product endorsement purposes.

\section{Auspices Statement}

This work was performed under the auspices of the U. S. Department of Energy (DOE) by the University of California, Lawrence Livermore National Laboratory (LLNL) under Contract No. W-7405-Eng-48. 


\title{
High-Energy Neutron Imaging Development at LLNL
}

\author{
James Hall (PI), Brian Rusnak and Peter Fitsos
}

\author{
Lawrence Livermore National Laboratory, P.O. Box 808, M/S L-050, Livermore, CA 94551-9900
}

\begin{abstract}
We are proceeding with the development of a high-energy (10 MeV) neutron imaging system for use as an inspection tool in nuclear stockpile stewardship applications. Our goal is to develop and deploy an imaging system capable of detecting cubic-mm-scale voids, cracks or other significant structural defects in heavily-shielded low-Z materials within nuclear device components. The final production-line system will be relatively compact (suitable for use in existing or proposed facilities within the DOE complex) and capable of acquiring both radiographic and tomographic (CT) images. In this report, we will review our programmatic accomplishments to date, highlighting recent (FY06) progress on engineering and technology development issues related to the proposed imaging system. We will also discuss our preliminary project plan for FY07, including engineering initiatives, proposed radiation damage experiments (neutrons and $\mathrm{x}$ rays) and potential options for conducting classified neutron imaging experiments at LLNL.
\end{abstract}

\section{Introduction}

We are proceeding with the development of a highenergy $(10 \mathrm{MeV})$ neutron imaging system for use as an inspection tool in nuclear stockpile stewardship applications associated with NNSA's Enhanced Surveillance Campaign (ESC). Our goal is to develop and deploy an imaging system capable of detecting cubic-mm-scale voids, cracks or other significant structural defects in heavily-shielded low-Z materials within nuclear device components. Potential applications for this new diagnostic include: (1) collection of baseline data characterizing the "as-designed" vs. "as-built" configurations of stockpiled systems, (2) routine surveillance of stockpiled systems to identify units that may need to be refurbished, (3) inspection and/or re-certification of device components rebuilt under proposed Lifetime Extension Programs (LEPs), (4) non-destructive damage assessment of weaponized assemblies following Stockpile-to-Target Sequence (STS) engineering tests and (5) screening to select appropriate destructive-test units and/or units for potential nuclear stockpile reductions if mandated. While high-energy neutron imaging can detect structure in thick objects which may be essentially opaque to conventional x-ray systems, we would like to emphasize that our intent here is to develop an inspection system that will complement - not replace - existing or proposed ESC x-ray diagnostic tools.

The final production-line imaging system will be relatively compact (suitable for use in existing or proposed inspection facilities within the DOE complex) and capable of acquiring both radiographic and tomographic (CT) images of device components. It will consist of an intense, accelerator-driven $\mathrm{D}(\mathrm{d}, \mathrm{n})^{3} \mathrm{He}$ neutron source $\left(\mathrm{E}_{\mathrm{n}} \approx 10 \mathrm{MeV} @ 0^{\circ}\right)$ with an effective yield of $\approx$ $10^{11} \mathrm{n} / \mathrm{sec} / \mathrm{sr}$ along the beam axis and a focal spot size of $\leq 1.50 \mathrm{~mm}$ (FWHM), a multi-axis R/T stage to support and manipulate objects under inspection and a neu- tron imaging detector ( $c f$. Figure 1). The detector itself will consist of a simple plastic scintillator (e.g. BC-408) viewed indirectly by a single large-format $C C D$ camera located in a well-shielded environment. The ultimate spatial resolution of the system is expected to be $\leq 1.00$ $\mathrm{mm}$ (FWHM) at the object position.

The conceptual design of the proposed system and results from a wide variety of unclassified neutron imaging experiments conducted at the Ohio University Accelerator Laboratory (OUAL) in Athens, $\mathrm{OH}$, using a relatively simple prototype imaging detector have already been published in the open literature [1 - 6] or summarized in previous ESC reports. In this report, we will review our programmatic accomplishments to date, highlighting recent (FY06) engineering and technology development issues related to the proposed imaging system. We will also discuss our preliminary project plan for FY07, including engineering initiatives, proposed radiation damage experiments (neutrons and $\mathrm{x}$ rays) and potential options for conducting classified neutron imaging experiments at LLNL.

\section{Source Development}

The development of an intense, high-energy neutron source suitable for use in a full-scale, productionline imaging system is critical to the success of this project. As noted above, we propose to use an accelerator-driven $\mathrm{D}(\mathrm{d}, \mathrm{n})^{3} \mathrm{He}$ neutron source operating at $\approx 10$ $\mathrm{MeV}$. In order to meet our performance requirements, the source will need to have an effective yield of $\approx 10^{11}$ $\mathrm{n} / \mathrm{sec} / \mathrm{sr}$ along the beam axis and an effective focal spot size of $\leq 1.50 \mathrm{~mm}$ (FWHM). While this is certainly achievable using existing (i.e. commercial and low-risk) technologies, it does pose some challenging technical problems, particularly in the design of the $\mathrm{D}_{2}$ gas target endstation and residual beam stop. 


\subsection{Accelerator Design}

The accelerator system that we propose to use in our full-scale neutron source will be based on mature, commercially-available technology. It will consist of a $\mathrm{D}^{+}$ion source and a pair of compact radio-frequency quadrupoles (RFQs) coupled to a short drift-tube linac (DTL) ( $c f$. Figure 2). The system will accelerate $\mathrm{D}^{+}$ions to an energy of $\approx 7 \mathrm{MeV}$ and be capable of delivering an average ion current of $\approx 325 \mu \mathrm{A}$ to a $\mathrm{D}_{2}$ gas cell located in the target endstation. The beam pulse frequency will be $\approx 140 \mathrm{~Hz}$ and the duty factor will be $\approx$ $1.95 \%$ (this implies a peak current of $\approx 15-17 \mathrm{~mA}$ and a pulse width of $\approx 139 \mu \mathrm{sec})$. The beam emittance $\left(\varepsilon_{x, y}\right)$ will be held to $\leq 4 \pi \mathrm{mm}$-mrad in order to achieve the small focal spot size required for imaging.

The full-up design for this accelerator system was completed during Q4 of FY02 by the proposed vendor, AccSys Technologies, Inc. of Pleasanton, CA, under a sole-source contract from LLNL. The design (essentially an extrapolation of a production-line AccSys machine) was subsequently reviewed and accepted by our Project Engineer (B. Rusnak) during Q1 of FY03. The projected cost of the installed system at that time was $\approx$ $\$ 2.5 \mathrm{M}$ (now estimated at $\approx \$ 2.9 \mathrm{M}$ due to inflation) and the estimated lead time for fabrication and final delivery was $\approx 12-18$ months [7].

\subsection{HEBT System}

The initial (conceptual) design of the high-energy beam transport (HEBT) system needed to transport and focus $\mathrm{D}^{+}$ions from the accelerator into the target endstation was developed using the charged particle transport code TRACE3D during Q1 of FY03 ( $c f$. Figure 3); however, following the guidance of ESC management at LLNL, we have elected to focus our effort and available funding since that time on the development of other system components that involve relatively higher technical risk and/or longer lead times. Finalizing the design of the HEBT system (i.e. identifying specific, commercially-available focusing elements compatible with our beam transport requirements and then integrating them into the overall system design) is not expected to be a particularly challenging problem.

\subsection{Endstation Design}

The simultaneous requirement for a large average $\mathrm{D}^{+}$ion current $(\approx 325 \mu \mathrm{A})$ and a relatively small focal spot size ( $\leq 1.50 \mathrm{~mm}$ (FWHM)) imposed by our proposed imaging application effectively precludes the use of a conventional (i.e. "windowed") $\mathrm{D}_{2}$ gas cell in the target endstation due to the fact that there simply exist no window materials capable of handling the extremely large areal power densities that we anticipate with our source $\left(\right.$ e.g. $\approx 130 \mathrm{~kW} / \mathrm{cm}^{2}$ (average), $\approx 6600 \mathrm{~kW} / \mathrm{cm}^{2}$ (peak)); therefore, we have focused our effort thus far on the development of "windowless" $\mathrm{D}_{2}$ gas cell designs which can be incorporated into the endstation and coupled to our pulsed-beam accelerator system for use as an intense neutron source.

One of the most promising ways to deal with large average or peak areal power densities is to use a "rotating-aperture" (RA) gas cell design. In this type of system, narrow ( $\approx 4-5 \mathrm{~mm}$ diameter) entrance and exit apertures on the stationary high-pressure $(\approx 3$ atma) gas cell (and any adjacent differential pumping stages) are "open" only when they happen to coincide with matching apertures in a series of rotating disks synchronized to the pulse frequency of the accelerator beam. This effectively isolates the high-pressure gas in the cell from the accelerator vacuum system. Pioneering research conducted at MIT [8 - 11] demonstrated that even a rudimentary RA system can create a very effective "plug" between a pressurized gas cell and a differential pumping system and work done at the DeBeers Diamond Research Laboratory in South Africa [12] has since proven the effectiveness of RA systems in production-line imaging applications.

Our current $\left(2^{\text {nd }}\right.$ generation) gas cell design is a multi-stage RA system that utilizes a 4-cm-wide crossflow $\mathrm{D}_{2}$ venturi capped at either end by 5 -mm-diameter rotating apertures ( $c f$. Figure 4$)$. If the venturi is capable of generating sufficiently high flow rates (e.g. $\approx 200$ $400 \mathrm{~m} / \mathrm{s})$, the $D_{2}$ gas in the beam channel $(\leq 1.50 \mathrm{~mm}$ FWHM) can be effectively refreshed $\geq 20$ times during the course of a single beam pulse $(\approx 139 \mu \mathrm{sec})$, thereby mitigating potential density rarefactions in the gas due to beam heating (i.e. "burn through") and the attendant decrease in neutron yield that one might normally expect for a given incident beam current and gas cell pressure. Detailed ALE3D gas hydrodynamic calculations done during FY04 confirmed that it should indeed be possible to maintain a $\mathrm{D}_{2}$ gas density in the beam channel equivalent to an average pressure of $\approx 3$ atma using this approach ( $c f$. Figure 5). This, in turn, should allow us to achieve a neutron yield which is $\geq 90 \%$ of the desired level (cf. Figure 6).

A full-scale prototype of this gas cell was built by a precision shop, the CHAMP Company of Campbell, CA, and delivered to LLNL at the end of Q3 of FY04 (cf. Figure 7). It was subsequently installed in a vacuum enclosure equipped with a variety of diagnostic sensors (cf. Figure 8) and used in a series of static pressure tests (since they have similar thermodynamic and hydrodynamic properties, $\mathrm{He}$ gas was used as a surrogate for $\mathrm{D}_{2}$ in these tests). Our primary objective in designing and building this test unit was to verify that we could achieve a gap spacing of $\leq 0.002$ " between a high-speed rotor ( $\geq 1000 \mathrm{RPM})$ and a stator (i.e. the venturi in our case). The width of the gap will be a critical factor in 
mitigating leak rates from the high-pressure $(\approx 3$ atma) gas cell and maintaining a low base pressure in the endstation (our goal is $\leq 25$ Torr). In order to facilitate these measurements, the venturi that would normally be used in a production-line endstation was replaced by a rectangular cross-flow tube with a straight throat in this particular unit ( $c f$. Figure 9). The opposing surfaces of the rotors and cross-flow tube were hard anodized with alumina, allowing them to be lapped and then precision ground for smoothness and flatness.

After an initial "break-in" period (during which the original baffled rotor assemblies were replaced by solid rotors due to a mechanical failure), the prototype RA system worked as intended. A series of measurements done using both optical and RF resonance techniques established that the gap between the high-speed rotors and stators in our prototype could be held to $\leq 0.002$ ", even when the system was run at high gas pressure $(\geq 3$ atma). Two different series of high pressure tests were run, each covering a range of $\approx 0.125-3.150$ atma. In the first series, the rotors were held fixed with the apertures misaligned (i.e. "closed"). Gas leakage was limited to the narrow gap between the rotors and stators in this case and was measured to be $<16$ Torr when the cross-flow tube was pressurized to $\approx 3$ atma. In the second series of tests, the rotors were run at a typical operating speed $(\approx 1000 \mathrm{RPM})$. The overall leakage in this case was measured to be $<75$ Torr when the cross-flow tube was pressurized to $\approx 3$ atma. While the operational base pressures measured in these tests were higher than our goal value (i.e. $\leq 25$ Torr), the results were nonetheless very encouraging and they allowed us to develop simple but accurate analytical models for calculating gas leakage in RA systems ( $c f$. Figure 10).

Based on lessons learned during the assembly and testing of this initial unit, we developed the conceptual design for a $3^{\text {rd }}$ generation RA gas cell during Q4 of FY05 ( $c f$. Figure 11). Our revised design will use the same drive motor and mounting scheme as before, but it will have high-tolerance thrust bearings integrated directly into the block which houses the high-pressure venturi cross-flow tube and a higher pumping capacity (e.g. $\approx 90 \mathrm{l} / \mathrm{s}$ vs. $\leq 35 \mathrm{l} / \mathrm{s}$ for the initial unit). We believe that these modifications will allow us to maintain a gap spacing of $<0.001$ " between the rotors and stators and an overall base pressure in the endstation of $\leq 10$ Torr, even when the system is run at high gas pressures $(\geq 3$ atma). An additional rotor assembly will also be added just downstream from the target gas cell to help isolate the $\mathrm{D}_{2}$ target gas from the Ar or Xe gas proposed for use as a beam stop (discussed in the next section). The engineering design for this system was finalized during FY06 and a detailed mechanical drawing package has been completed. We are, in principal, ready to proceed with the fabrication of a $3^{\text {rd }}$ generation test unit at any time; however, progress on this task will depend on our FY07 funding level and project priorities.

In conjunction with finalizing the engineering design work on our $3^{\text {rd }}$ generation RA gas cell, substantial effort was also expended during FY06 to analyze the $\mathrm{D}_{2}$ target gas flow dynamics of the system and develop specifications for a gas handling system that will meet our requirements $(i . e . \approx 200-400 \mathrm{~m} / \mathrm{s}$ gas flow through the venturi at a continuous pressure of $\approx 3$ atma), with the primary goal being to identify specific " $\mathrm{D}_{2}$-rated" compressor systems that could be used. The best suited, commercially-available system appears to be a 293 SCFM, 3-stage pump manufactured by PDC Machines, Inc. of Warminster, PA, which consists of a compressor, two accumulators, a heat exchanger, several isolation valves and two regulators. While this system will certainly meet our requirements, its size (12' (L) X 5' $\left.(\mathrm{W}) \mathrm{X} 7^{\prime}(\mathrm{H})\right)$ and cost $(\approx \$ 155 \mathrm{k})$, combined with the relatively large volume of $\mathrm{D}_{2}$ needed to operate the system (nominally $\approx 16.5 \mathrm{SCF}$ ), are potential drawbacks which have motivated us to investigate alternate ways to put gas in front of the beam.

One alternate approach currently being considered is the possibility of using a "pulsed gas injection" system in which $\mathrm{D}_{2}$ gas is pressurized via natural dynamic flow processes in the gas handling system and then injected into the target gas cell through a rotating valve assembly only when beam is present. This sort of system (which would not necessarily involve the use of rotating apertures to cap the gas cell) would be well suited for use with a pulsed-beam accelerator (e.g. our proposed RFQ/DTL system) and, based on our preliminary calculations, could potentially meet our target gas density requirements (i.e. $\approx 3$ atma equivalent during the beam pulse) with $D_{2}$ gas volumes and pumps which are an order of magnitude or more smaller than those required for our RA gas cell. A conceptual design for such a system was developed during Q4 of FY06 and will be further refined during FY07.

\subsection{Beam Stop}

After the incident $\mathrm{D}^{+}$ion beam passes through the $\mathrm{D}_{2}$ gas cell in the endstation, its residual energy needs to be dissipated in a way that not only has minimal impact on the intensity and spatial distribution of the primary (quasi-monoenergetic) neutron beam generated in the gas cell, but which also produces as few additional (broad-spectrum) neutrons as possible. Two different ways of doing this - each with distinct advantages and disadvantages - have been investigated, beginning in Q4 of FY05 and continuing through FY06.

The first approach considered involved dissipating the beam energy in a conventional solid beam stop fabricated from a high- $\mathrm{Z}$ refractive metal $(e . g . \mathrm{W})$. While this would seem to be the most straight-forward ap- 
proach from a purely mechanical perspective, extensive energy deposition and analytical heat flow calculations done on both "grazing incidence" and "suspended nipple" type beam stop designs indicated that the incident beam energy could not be dissipated without resorting to the use of materials so thick that they would almost certainly have a significant (negative) impact on the intensity and spatial distribution of the primary neutron beam. Additional problems posed by deuterium implanted in the beam stop and operational safety issues (e.g. the potential for spontaneous $\mathrm{D}_{2}$ combustion in the event of a vacuum failure) have lead us to shelve this approach for the time being.

The second approach considered - and our current focus - involves dumping the residual beam into a highpressure ( $\approx 3$ atma), high-Z gas such as Ar or Xe located in a cell immediately downstream from the $\mathrm{D}_{2}$ gas cell. The incident beam power $(\approx 2.28 \mathrm{~kW}$ (average) in our case) could then be removed by using a heat exchanger in the high-Z gas recirculation loop. Our calculations indicate that a 2 -stage rotating aperture located at the exit of the target gas cell will serve to minimize mixing between the two gases and the purity of the different gas streams could potentially be maintained by using a gas handling system that exploits differences in the thermodynamic transport properties of the gases. High-pressure Ar or Xe gas should have essentially no impact on either the intensity or the spatial distribution of the primary neutron beam and beam breakup measurements for $\mathrm{D}^{+}$ions incident on $\mathrm{Ar}$ and $\mathrm{Xe}$ gas have shown that neither produces a significant number of additional (broad-spectrum) neutrons; however, additional fluid hydrodynamics calculations similar to those done for the $\mathrm{D}_{2}$ gas cell are currently planned to ensure that beam "burn through" in the stopping gas and turbulent mixing between the target and stopping gases will not be problems.

\section{Detector Development}

The development of a high-efficiency, large-format neutron detector suitable for use in a full-scale, production-line imaging system is also critical to the success of this project. While the prototype detector developed for use in our experiments at OUAL has worked quite well thus far, allowing us to validate the potential of neutron imaging by capturing radiographic and tomographic images of a variety of test objects, its format is only $\approx 30 \mathrm{~cm}$ X $30 \mathrm{~cm}$. We estimate that a full-scale imaging detector will need to have a format $\geq 2$ times this size in order to meet the requirements of potential ESC device inspection scenarios.

A preliminary design study related to this development process was completed during Q4 of FY04 by the proposed vendor, Optics1, Inc. of Westlake Village, CA, under a sole-source contract from LLNL. This study evaluated two different imaging options ( $c f$. Figure 12). The first option was based on a relatively complex, 4-camera detector similar to that recently built by Optics 1 for use in an ESC high-resolution x-ray imaging system intended for eventual deployment at Pantex. The second option used a much simpler (and lower cost) single camera detector similar to that currently being used in our imaging experiments at OUAL. The primary objectives of this study were to identify suitable commercial CCD cameras, develop preliminary designs for the associated fast optical lens systems and predict the limiting spatial resolutions and signal-tonoise $(\mathrm{S} / \mathrm{N})$ ratios for each case.

Based on the results of this study, we chose to go with the second option (i.e. a single camera detector) and proceeded to work with Optics 1 through the course of FY05 and into early FY06 to finalize the engineering design of the system and define specifications for key components. Our full-scale prototype of the detector (cf. Figure 13) will consist of $\mathrm{a} \approx 2-4 \mathrm{~cm}$ thick, $65 \mathrm{~cm}$ $\mathrm{X} 65 \mathrm{~cm}$ plastic scintillator (e.g. BC-408) viewed by a single large-format CCD camera. A thin ( $\approx 0.125$ ") Pyrex turning mirror with an aluminized front surface will be used to redirect light from the scintillator into the camera, thereby allowing it to be located off axis in a relatively well-shielded environment (i.e. out of the direct neutron beam path). The entire detector system will be mounted on a single 4' X 5' optical table and enclosed in a light-tight housing (not shown in figure).

The lens assembly that will be used in the detector (cf. Figure 14) was built by Optics1 during FY06 and has been designed to provide high light collection efficiency $(\approx f / 1.25)$ and uniform focus over the full $65 \mathrm{~cm}$ $\mathrm{X} 65 \mathrm{~cm}$ field of view at the scintillator. A high-speed electronic shutter will also be provided by Optics 1 to prevent stray light from entering the lens between image frames. Delivery of these components to LLNL is expected by the end of Q1 of FY07 (following the completion of acceptance tests at Optics1).

The CCD camera, currently on order from Spectral Instruments, Inc. of Tucson, AZ, will utilize a Fairchild 4096 X $4096(15 \mu \mathrm{m})$ pixel, back-illuminated imaging sensor with a "UV-enhanced" anti-reflective coating optimized for BC-400/BC-408 spectral sensitivity ( $c f$. Figure 15). It will have a 4-port parallel readout system with 16-bit digitization and the sensor will be cryogenically cooled to $\approx-100{ }^{\circ} \mathrm{C}$, which will effectively eliminate thermal noise and enable long $(\leq 1 \mathrm{hr}$ ) integration times if desired. It should be noted that, since the ultimate spatial resolution of an imaging detector such as the one we are building here is usually limited by either source spot size or the intrinsic resolution of the scintillator, we will not necessarily be able to take advantage of the high resolution that would normally be afforded by a $4096 \mathrm{X} 4096(15 \mu \mathrm{m})$ chip; however, this particular sensor was chosen because its physical size $(61.45$ 
$\mathrm{mm}$ X $61.45 \mathrm{~mm}$ ) significantly enhances the camera's overall sensitivity. Delivery of this system to LLNL is expected during Q2 of FY07.

Our full-scale detector will be larger in scale but, as noted earlier, is conceptually similar to that currently being used in our imaging experiments at OUAL and, based on design calculations done by Optics1, it should be capable of providing a spatial resolution of $\leq 1 \mathrm{~mm}$ (FWHM) at the object position (which, while not as good as some $\mathrm{x}$-ray imaging systems, is thought to be adequate for our proposed application). The predicted $\mathrm{S} / \mathrm{N}$ ratio for the full-scale detector should be $\approx 82 \mathrm{X}$ that of our current prototype at OUAL.

\section{FY07 Project Plan}

Since DOE is currently operating under a "continuing resolution" with Congress, the DOE/NNSA budget for FY07 - and, hence, our FY07 project budget - has not been finalized at the time of this report. The following project plan should, therefore, be considered to be "preliminary" at best.

As in FY06, we propose to expend the majority of our effort during the coming year on what we believe to be key engineering and technology development issues related to our proposed high-energy neutron imaging system. One issue that we would like to continue to address is neutron source development. We propose to refine the design and develop accurate analytical models for the "pulsed gas injection" system that we suspect might be more efficient than our proposed $3^{\text {rd }}$ generation RA gas cell at putting $\mathrm{D}_{2}$ gas in front of the beam. If funding allows and our calculations confirm that it is a viable alternative, we would then proceed to build a full-scale prototype of a "pulsed gas injection" system for use in dynamic pressure tests at LLNL.

The second issue that we would like to continue to address is imaging detector development. All of the key components of a full-scale detector system will be in hand at LLNL by the end of Q2 of FY07. We would like to hire an optics engineer to lead the effort of integrating these components into a working system by the end of Q3 of FY07. If funding allows, the system would then be field-tested at LLNL and/or OUAL.

While no new (unclassified) neutron imaging experiments have been proposed for FY07 by ESC management, we have recently proposed the possibility of conducting a short series of relatively simple experiments to assess potential radiation damage effects in ESC-relevant low-Z materials exposed to high-energy neutrons and $\mathrm{x}$ rays. These experiments, which could easily be done at OUAL (10 MeV neutrons) and LLNL (9 MeV e-Bremsstrahlung), would involve exposing a select assortment of vacuum-sealed low- $Z$ materials (perhaps only $10-12$ ) to neutron and x-ray dose levels representative of those that they might see in a produc- tion-line ESC device inspection scenario. The samples would then be analyzed for radiation damage (e.g. corrosive gas evolution, structural changes, etc.) by independent experts at LLNL and/or LANL. While we have conducted similar sorts of high-energy neutron experiments before, there appear to be little or no corresponding data on high-energy x-ray exposure effects. These experiments could prove to be a valuable gauge of the risks posed by imaging diagnostics.

Finally, in light of the fact that funding for our proposed RFQ/DTL accelerator system may not be immediately forthcoming from NNSA, we will be investigating another source option during FY07 - the possibility of using a currently-mothballed 3 MV Tandem Pelletron located in one of the accelerator bays in B194 at LLNL. The Physics \& Advanced Technologies (PAT) Directorate at LLNL is planning to begin refurbishing this machine during FY07 and, depending on the availability of funds (theirs, not ours), they hope to bring it on-line sometime late in the FY. Although not as well suited to use in imaging applications as our proposed RFQ/DTL system, this machine will nonetheless accelerate $\mathrm{D}^{+}$ions to an energy of $\approx 6 \mathrm{MeV}$ and should be capable of delivering an average ion current of $\approx 100$ $\mu \mathrm{A}$ (DC) to a target. This means that we could, in principal, use an existing (windowed) $\mathrm{D}_{2}$ gas cell design to generate $\approx 8.5$ - $9 \mathrm{MeV}$ neutrons $@ 0^{\circ}$ with an effective yield along the beam axis several times larger than that currently available at OUAL which, in turn, raises the tantalizing possibility of conducting classified neutron imaging experiments at LLNL.

\section{Summary}

The wide variety of unclassified neutron imaging experiments conducted at OUAL thus far using our relatively simple prototype imaging detector, combined with classified Monte Carlo simulations of potential ESC imaging scenarios, have demonstrated the potential effectiveness of high-energy neutron imaging and validated its proposed use as a nonintrusive inspection tool in ESC applications. The engineering design for a full-scale neutron imaging system - largely based on commercially-available and/or relatively low-risk technologies and suitable for use in existing or proposed facilities within the DOE complex - is in a reasonably mature state of development and we are ready to commit to the construction of a full-scale prototype at LLNL when sufficient funds become available; however, our path forward here will ultimately depend on NNSA's timeframe for deciding on the composition of its " $211^{\text {st }}$ Century stockpile diagnostic suite" (e.g. X-ray $\mathrm{CT}+$ ?). If given authorization to proceed at this time, we believe that we could have a neutron imaging facility operational at LLNL by late FY09 or early FY10. This would allow us to continue to explore improved 
neutron source and imaging detector technologies while proceeding with the installation of production-line neutron imaging systems at selected sites with the DOE complex (operational $\geq$ FY11).

\section{Acknowledgments}

We would like to thank the ESC management team at LLNL, Drs. William McLean and Bryan Balazs, for their continued support and guidance. We would also like to thank the members of our mechanical design team, Stan Edson and Steve Arguello for their talented assistance and - in particular - our purchasing and contracts coordinator, Ray Souza, for his dedication and his amazing ability to work within the system at LLNL and get things done in a timely manner.

This work was performed at the University of California, Lawrence Livermore National Laboratory, under the auspices of the U.S. Department of Energy (contract \# W-7405-Eng-48).

\section{References}

1. F. Dietrich and J. Hall, "Detector concept for neutron tomography in the $10-15 \mathrm{MeV}$ energy range", LLNL doc. UCRL-ID123490 (LLNL, 1996).

2. F. Dietrich, J. Hall and C. Logan, "Conceptual design for a neutron imaging system for thick target analysis operating in the 10 - $15 \mathrm{MeV}$ energy range," UCRL-JC-124401 (LLNL, 1996), published in Proc. $14^{\text {th }}$ Int. Conf. on the Application of Accelerators in Research and Industry (Denton, TX, 1996), AIP CP392, ed. J. Duggan and I. Morgan, 837 (1997).

3. J. Hall, F. Dietrich, C. Logan and G Schmid, "Development of high-energy neutron imaging for use in NDE applications",
UCRL-JC-134562 (LLNL, 1999), published in Penetrating Radiation Systems and Applications (Denver, CO, 1999), SPIE 3769, ed. F. Doty, 31 (1999).

4. J. Hall, F. Dietrich, C. Logan and B. Rusnak, "Recent Results in the Development of Fast Neutron Imaging Techniques," UCRLJC-140435 (LLNL, 2000), published in Proc. $16^{\text {th }}$ Int. Conf. on the Application of Accelerators in Research and Industry (Denton, TX, 2000), AIP CP576, ed. J. Duggan and I. Morgan, 1113 (2001).

5. B. Rusnak and J. Hall, "An accelerator system for neutron radiography," UCRL-JC-139558 (LLNL, 2000), published in Proc. $16^{\text {th }}$ Int. Conf. on the Applications of Accelerators in Research and Industry (Denton, TX, 2000), AIP CP576, ed. J. L. Duggan and I. L. Morgan, 1105 (2001).

6. J. Hall, "Uncovering hidden defects with neutrons," published in Science \& Technology Review, May 2001 (LLNL, 2001).

7. R. Hamm, AccSys Technologies, Inc., private communication.

8. E. Iverson, R. Lanza and L. Lidsky, "Windowless gas targets for neutron production," Proc. $5^{\text {th }}$ Int. Conf. on Neutrons in Research and Industry (Crete, Greece, 1996), SPIE 2867, ed. G. Vourvopoulos, 513 (1996).

9. E. Iverson, "Windowless gas targets for neutron production," $\mathrm{Ph} . \mathrm{D}$. thesis (unpublished), Massachusetts Institute of Technology, Cambridge, MA, February 1997; R. Lanza, private communication.

10. W. Gerber, "Investigation of windowless gas target systems for particle accelerators," Master's thesis (unpublished), Massachusetts Institute of Technology, Cambridge, MA, June 1998; R. Lanza, private communication.

11. E. Empey, "Implementation of a closed-loop windowless gas target system for neutron production," Master's thesis (unpublished), Massachusetts Institute of Technology, Cambridge, MA, February 2000; R. Lanza, private communication.

12. J. Guzek, et al., "Development of High-Pressure Deuterium Gas Targets for the Generation of Intense Monoenergetic Fast Neutron Beams," Nuclear Instruments and Methods in Physics Research B, 152, 512 (1999).

\section{Collected Figures}

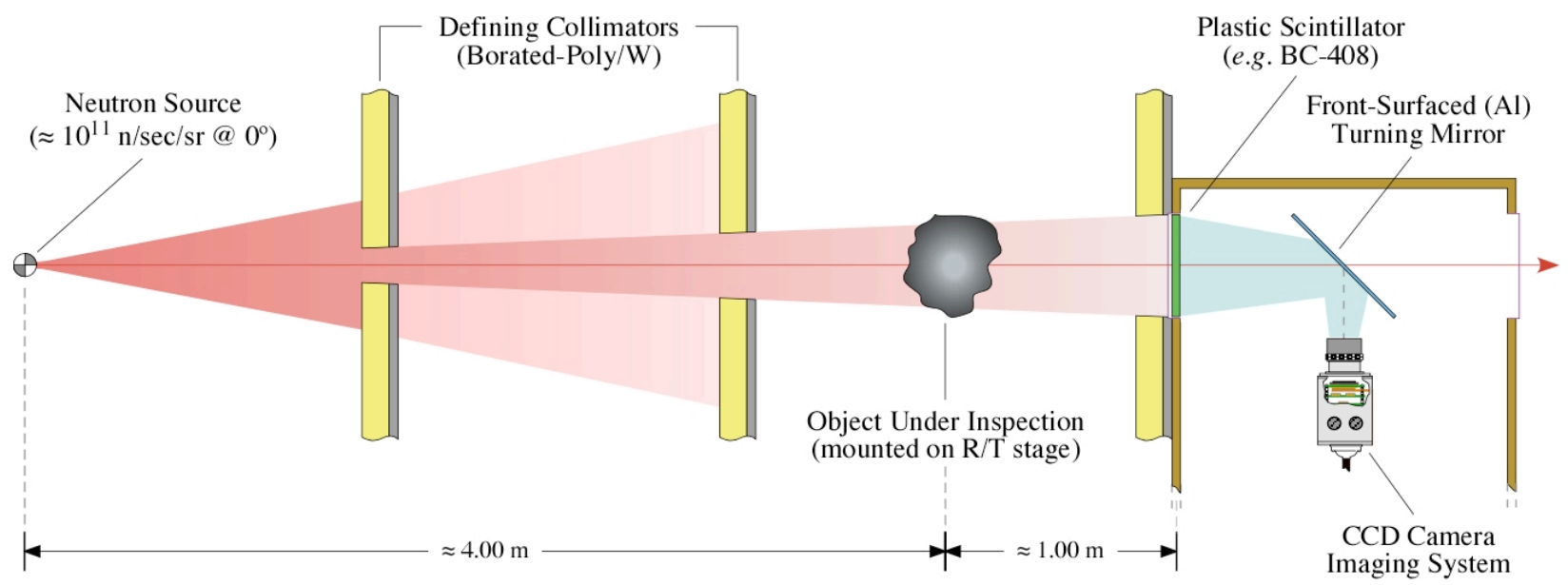

Figure 1: Conceptual design of proposed high-energy neutron imaging system. This representation shows the system with a 1.25:1 image magnification factor (similar to that proposed for use with ESC x-ray imaging diagnostics). Objects will be mounted on a R/T stage assembly that will allow either conventional radiographic or full tomographic (CT) imaging. 


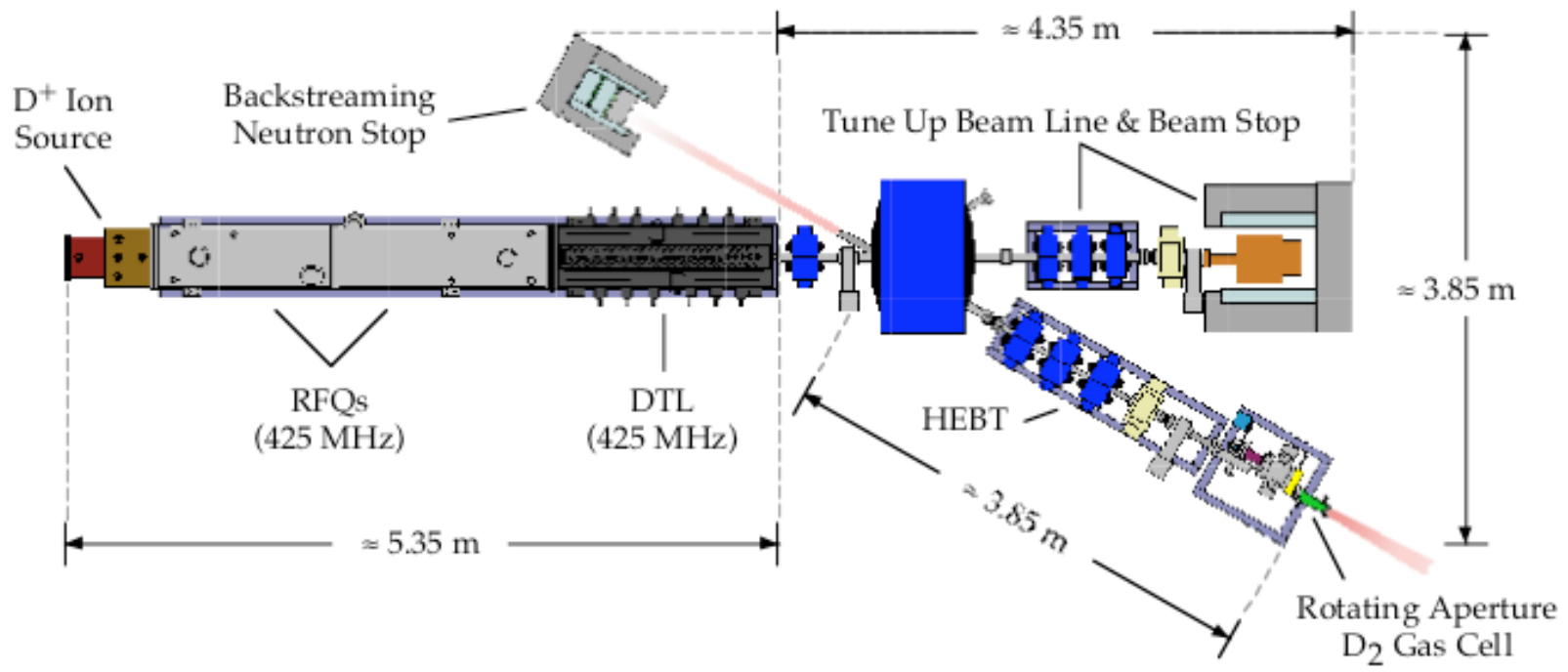

Figure 2: Schematic of proposed high-intensity neutron source. The full-scale, production-line system will consist of a $\mathrm{D}^{+}$ion source and a pair of compact, radio-frequency quadrupoles (RFQs) coupled to a short drift-tube linac (DTL). The high-energy beam transport (HEBT) system and $\mathrm{D}_{2}$ gas target endstation are also shown along with a tune-up beam line and beam stop.

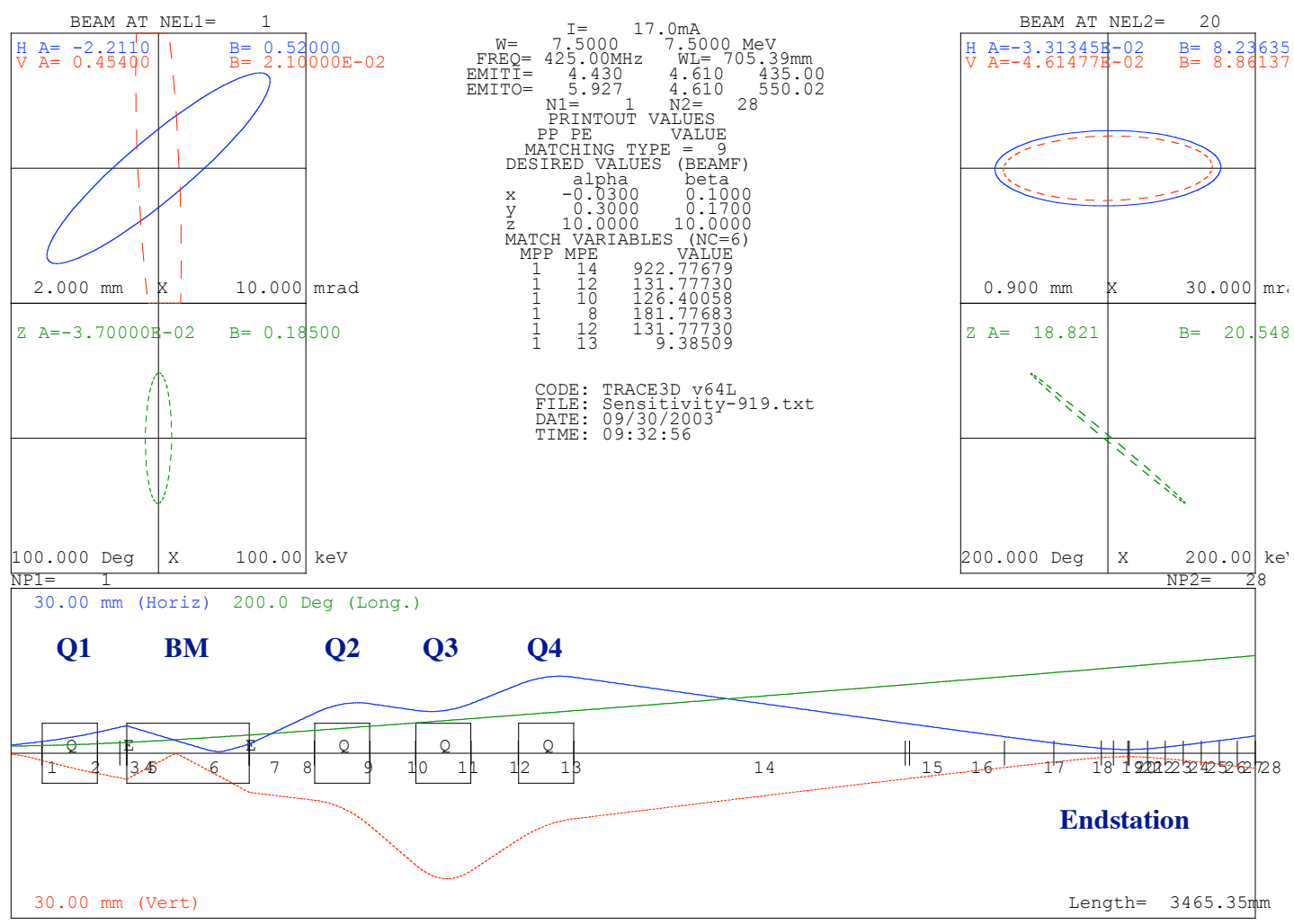

Figure 3: TRACE3D analysis of the conceptual HEBT design showing beam envelopes for $\approx 95 \%$ transmission through system. A horizontal plot is also shown which shows the relative positions of the first quadrupole, the bending magnet and the final quadrupole triplet designed to focus the beam into the target endstation (waist on the right). 


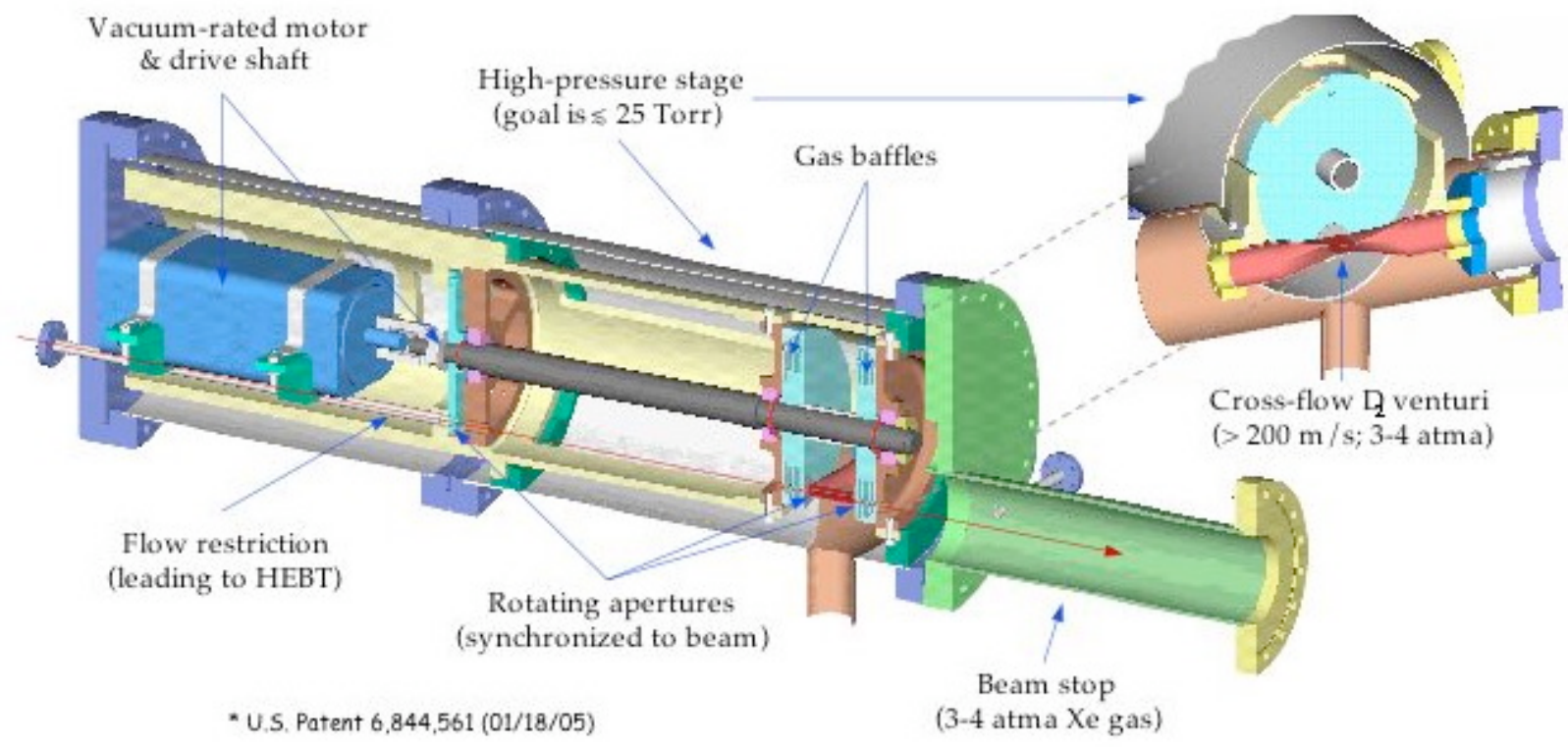

Figure 4: Current ( $2^{\text {nd }}$ generation) design of "rotating-aperture" $D_{2}$ gas target endstation.* A cross-flow $D_{2}$ venturi capped at either end by rotating apertures is used in this design to minimize the effect of density rarefactions associated with beam heating.
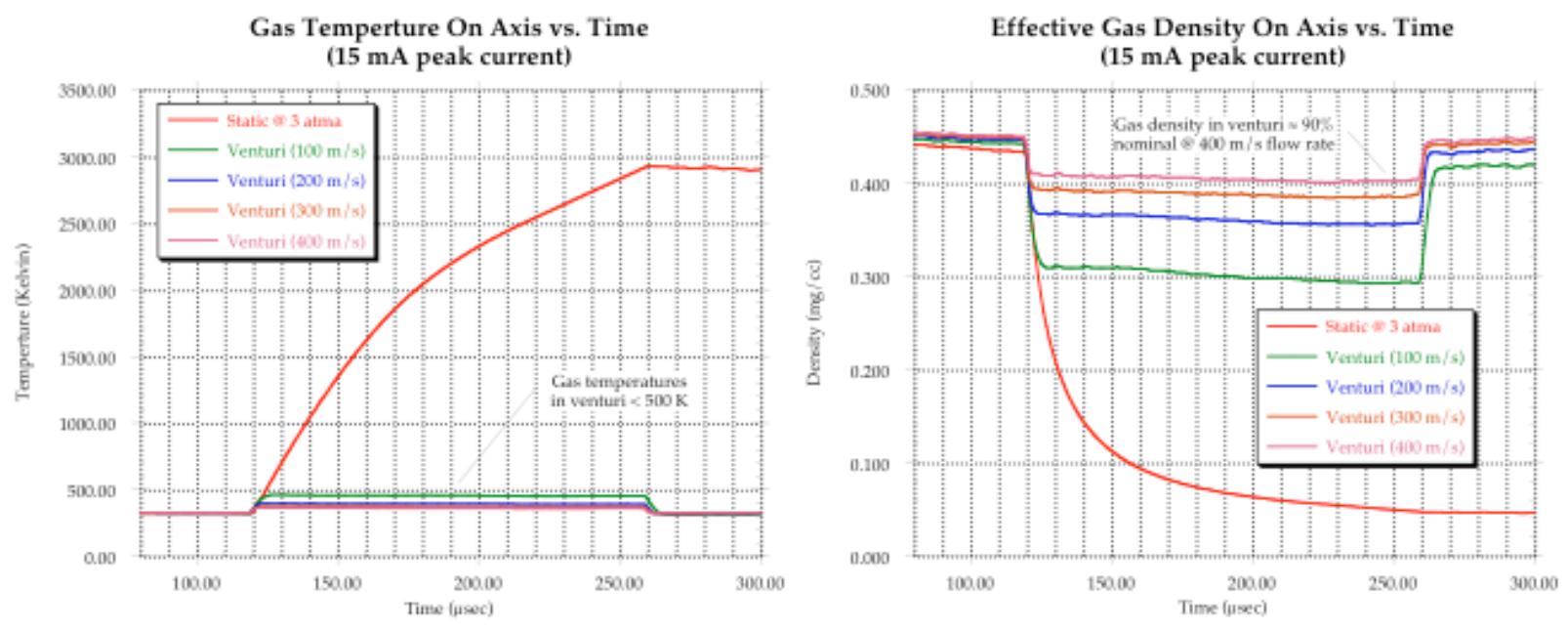

Figure 5: $\mathrm{D}_{2}$ gas temperature and density vs. time in the beam focus channel for revised endstation design. These results indicated that it should be possible to maintain a $\mathrm{D}_{2}$ gas density in the beam channel equivalent to an average pressure of $\approx 3$ atma. 


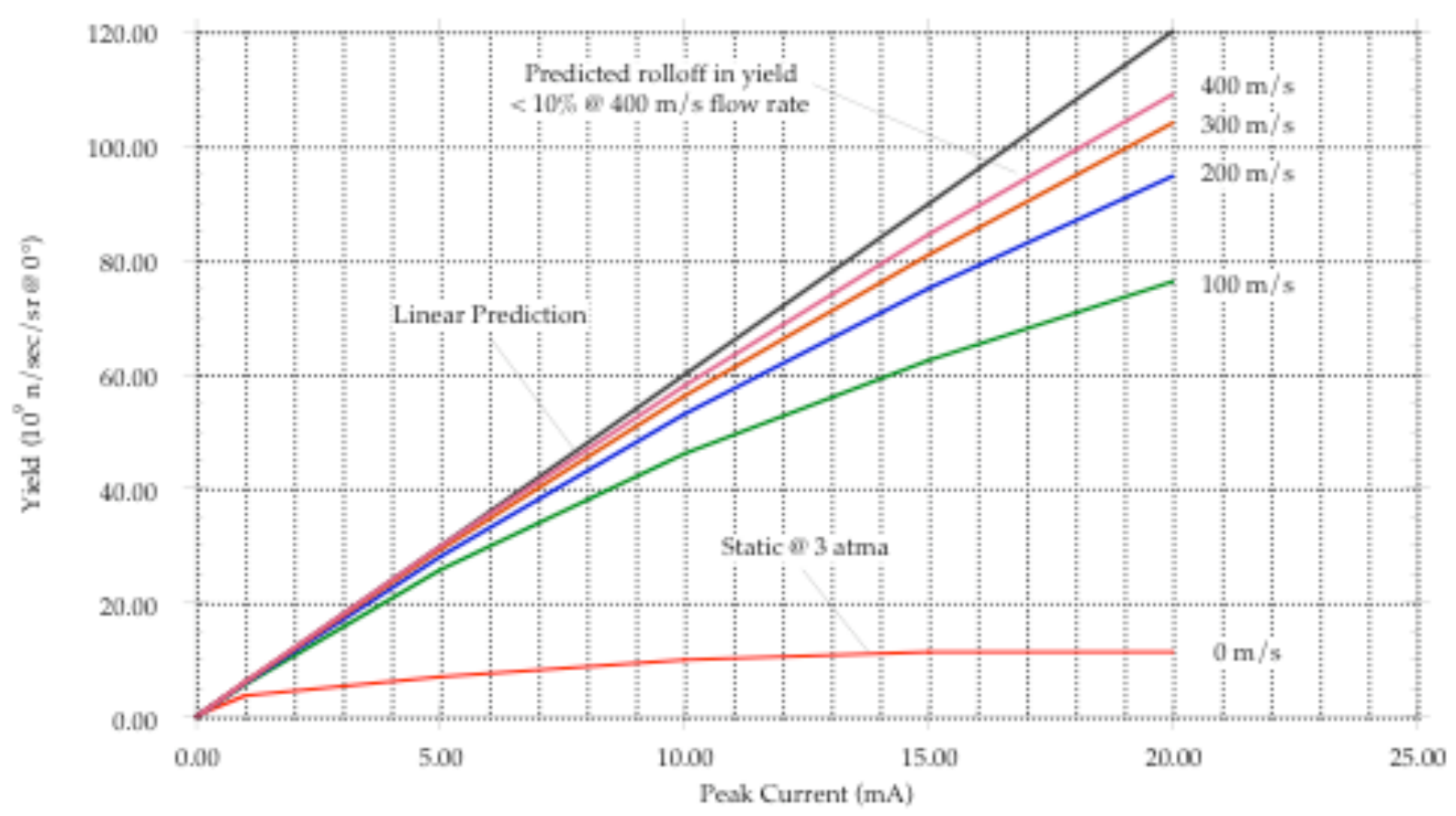

Figure 6: Predicted roll-off (relative to the expected value) in effective neutron yield due to $\mathrm{D}_{2}$ density rarefactions associated with beam heating. Note that the roll-off for a peak current of $\approx 17 \mathrm{~mA}$ (i.e. our proposed system) is predicted to be $<10 \%$ for a venturi gas flow rate of $\approx 400 \mathrm{~m} / \mathrm{s}$ (achievable with our proposed system).

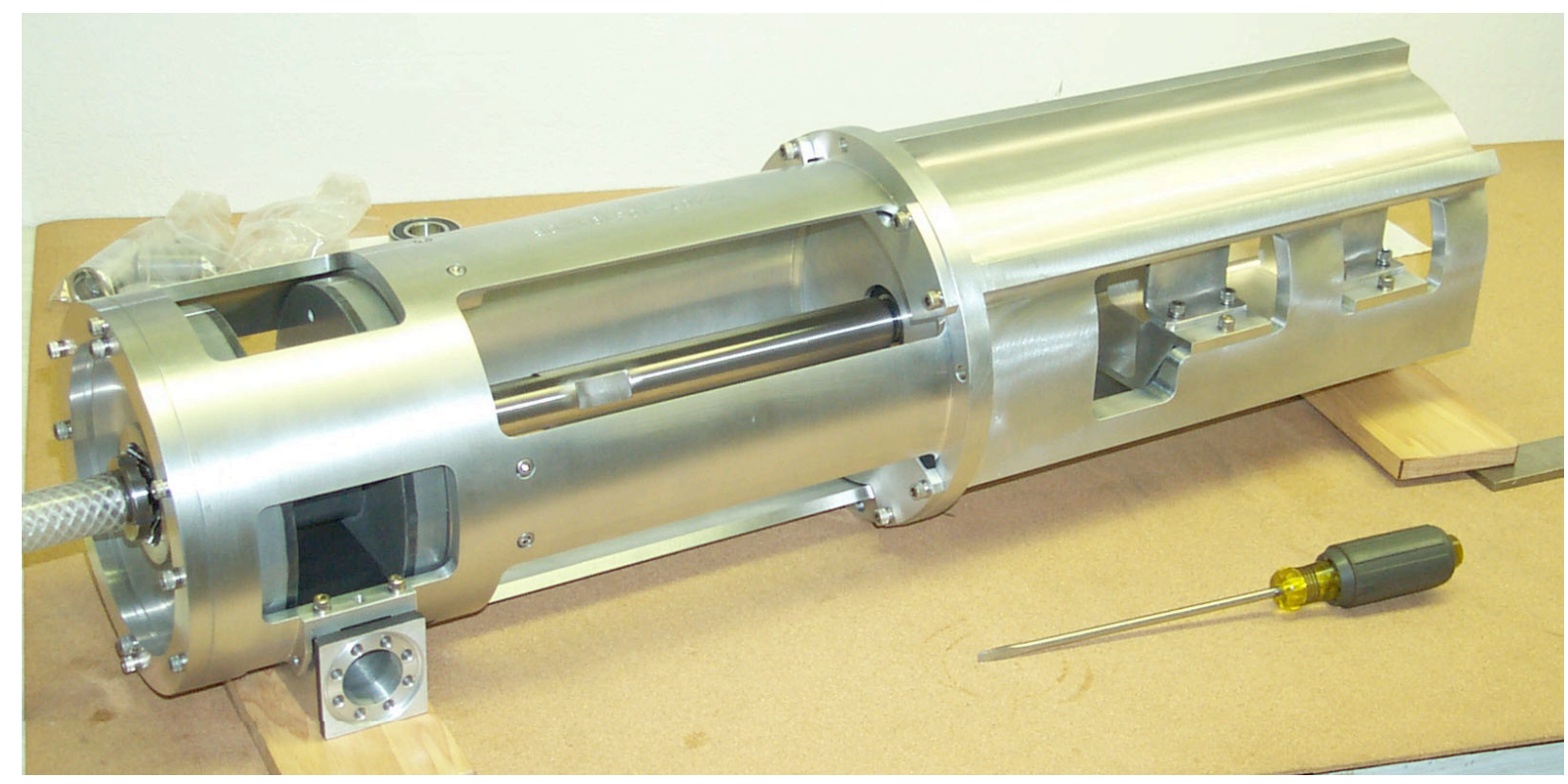

Figure 7: Full-scale prototype of target endstation built by the CHAMP Company of Campbell, CA and delivered to LLNL for use in performance tests. The one-piece, rigid aluminum sub-frame shown here allows us to align and hold the drive motor and all of the various precision parts that need to rotate at $\geq 1000$ RPM without the need to procure or fabricate special vacuum enclosures that can also be precision aligned. 


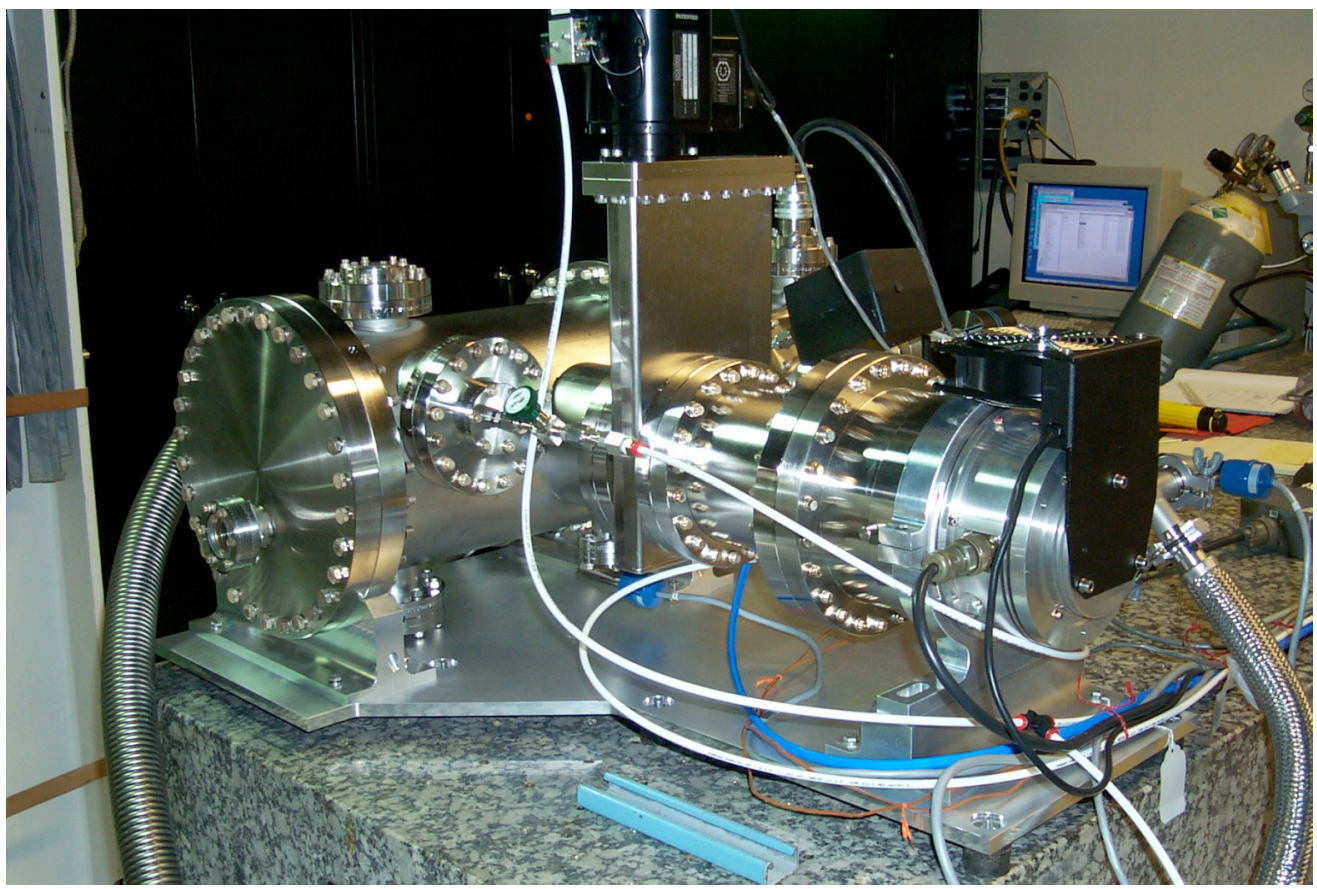

Figure 8: Prototype rotating-aperture endstation assembly installed in custom-designed vacuum enclosure equipped with pumps and diagnostic sensors. Pressure testing of this unit was conducted in a shared laboratory space located in B132S at LLNL.

Cutaway drawing of cross-flow tube between rotors

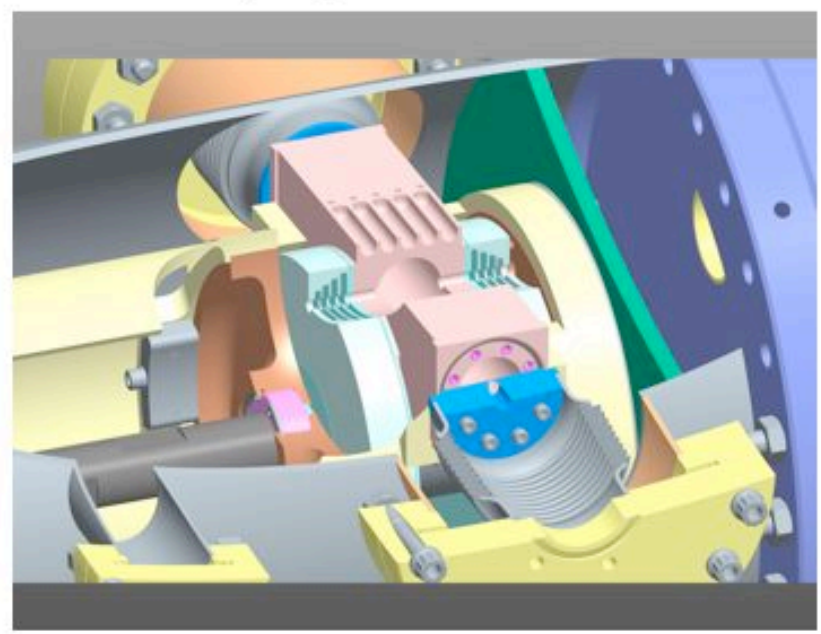

Prototype system (LLNL, B132S)

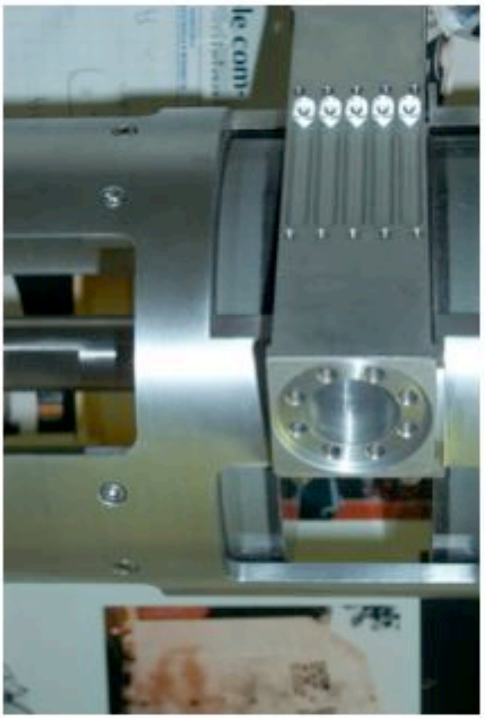

Figure 9: Cutaway drawing and photograph of cross-flow region in endstation flanked by baffled rotors. One of the primary goals in designing and fabricating these initial test units was to verify that we could achieve a gap spacing of $\leq 0.002$ " between these components. Note that the venturi that would normally be used in a production-line endstation was replaced by a rectangular cross-flow tube with a straight throat in this particular unit for use in tests with static gas. 


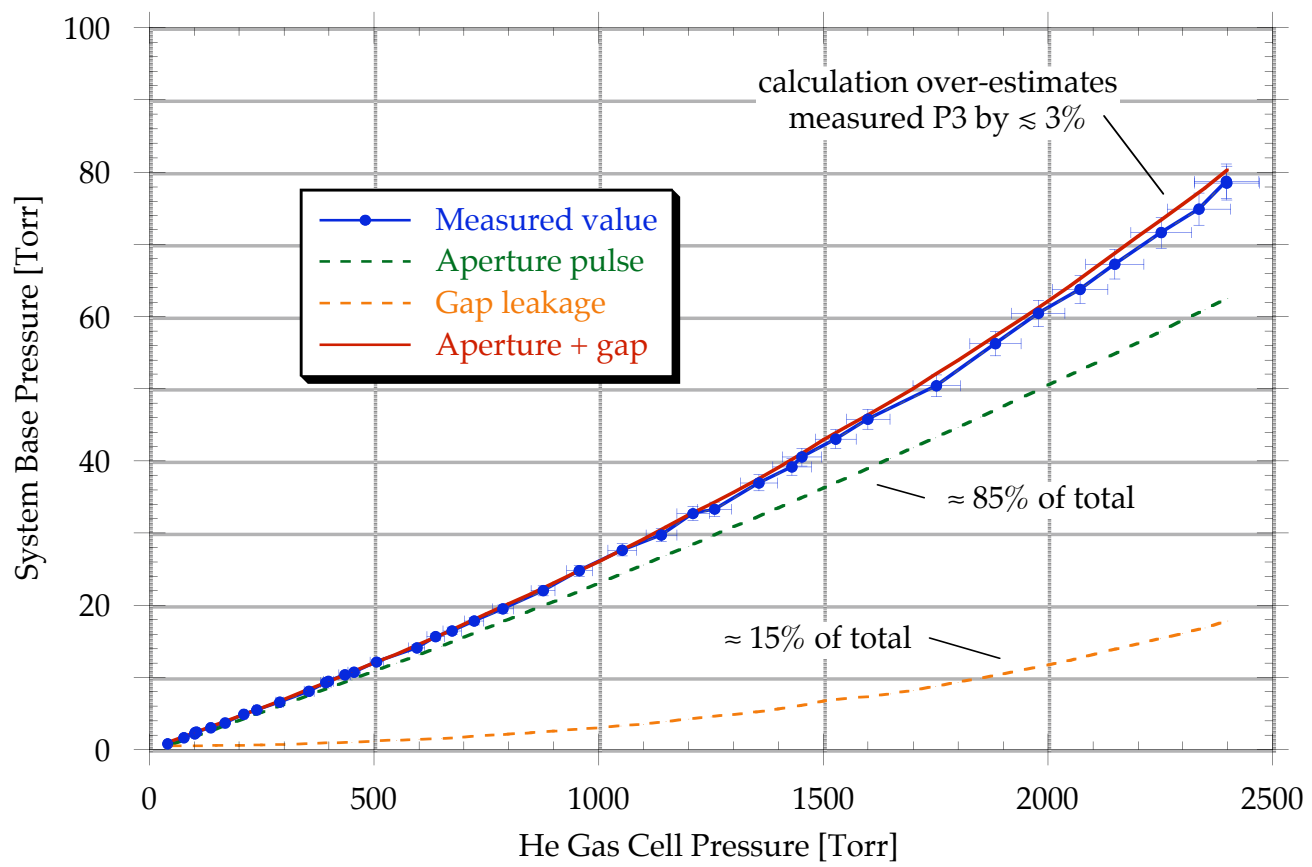

Figure 10: System base pressure vs. gas cell pressure for case of rotors run at typical operating speed $(\approx 1000$ RPM). The overall leak rate in this case was measured to be $<75$ Torr when the cross-flow tube was pressurized to $\approx 3$ atma (He). Note that the leak rates through the open apertures and the gap were both well approximated by our simple analytical models.

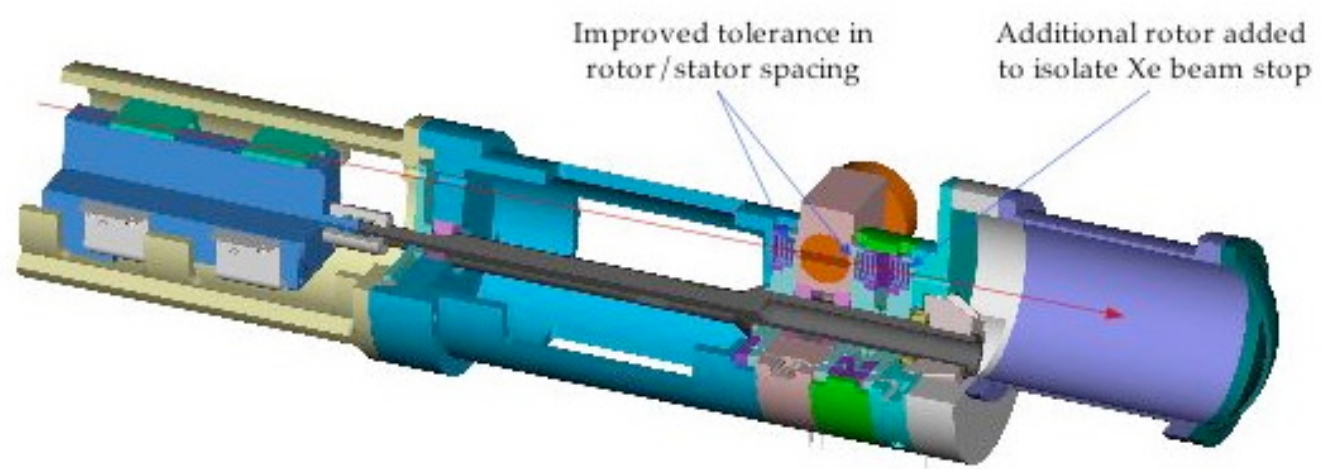

Figure 11: Cutaway drawing of conceptual design of $3^{\text {rd }}$ generation rotating aperture system. This system will use the same drive motor and mounting scheme as our test unit, but it will have high-tolerance thrust bearings integrated directly into the block which houses the high-pressure venturi cross-flow tube and a higher pumping capacity. An additional rotor assembly will also be added to help isolate the $\mathrm{D}_{2}$ target gas from the Ar or Xe gas proposed for use as a beam stop. 


\section{- Design option 1 :}

- $85 \mathrm{~cm} \mathrm{X} 85 \mathrm{~cm}$ FOV $(\mathrm{M} \approx 2: 1)$

- four camera array (2048 CCDs) - overlapping images

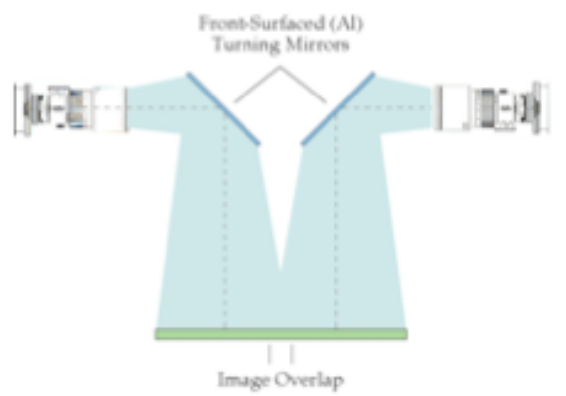

\section{- Design option 2 :}

- $65 \mathrm{~cm} \mathrm{X} 65 \mathrm{~cm}$ FOV (M $\approx 1.25: 1)$

- single camera (4096 CCD)

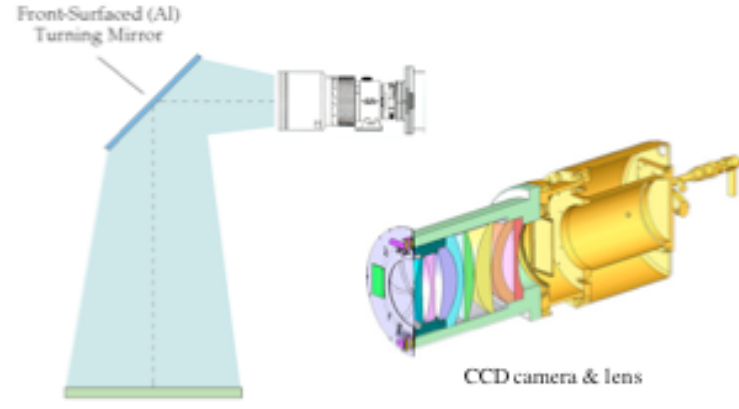

Figure 12: Design options evaluated for proposed full-scale imaging detector system. The first option (left) was based on a relatively complex, 4-camera detector similar to that recently built by Optics1 for use in an ESC high-resolution x-ray imaging system intended for eventual deployment at Pantex (note that image registration would have to be done off line in a secure environment in this case prior to analysis). The second option used a much simpler (and lower cost) single camera detector similar to that currently being used in our imaging experiments at OUAL. It offers comparable optical resolution to Option 1 and a much higher $\mathrm{S} / \mathrm{N}$ ratio; however, it is also limited to a somewhat smaller field of view.

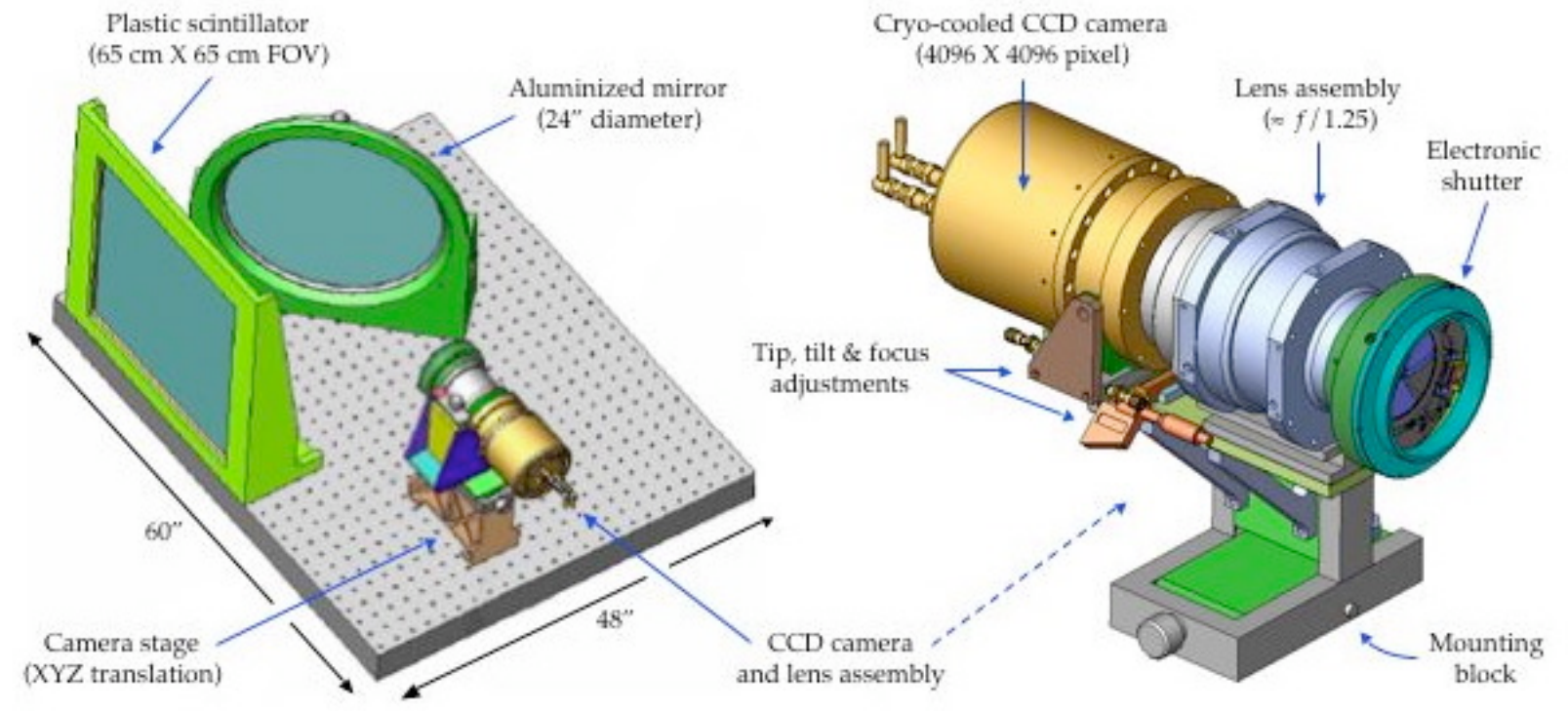

Figure 13: Planned layout for full-scale prototype of single camera imaging detector. The system will consist of a $\approx 2-4 \mathrm{~cm}$ thick, $65 \mathrm{~cm}$ X $65 \mathrm{~cm}$ plastic scintillator (e.g. BC-408) viewed by a single large-format CCD camera. A turning mirror with an aluminized front surface will be used to redirect light from the scintillator into the camera, thereby allowing it to be located off axis in a relatively well-shielded environment (i.e. out of the direct neutron beam path). 


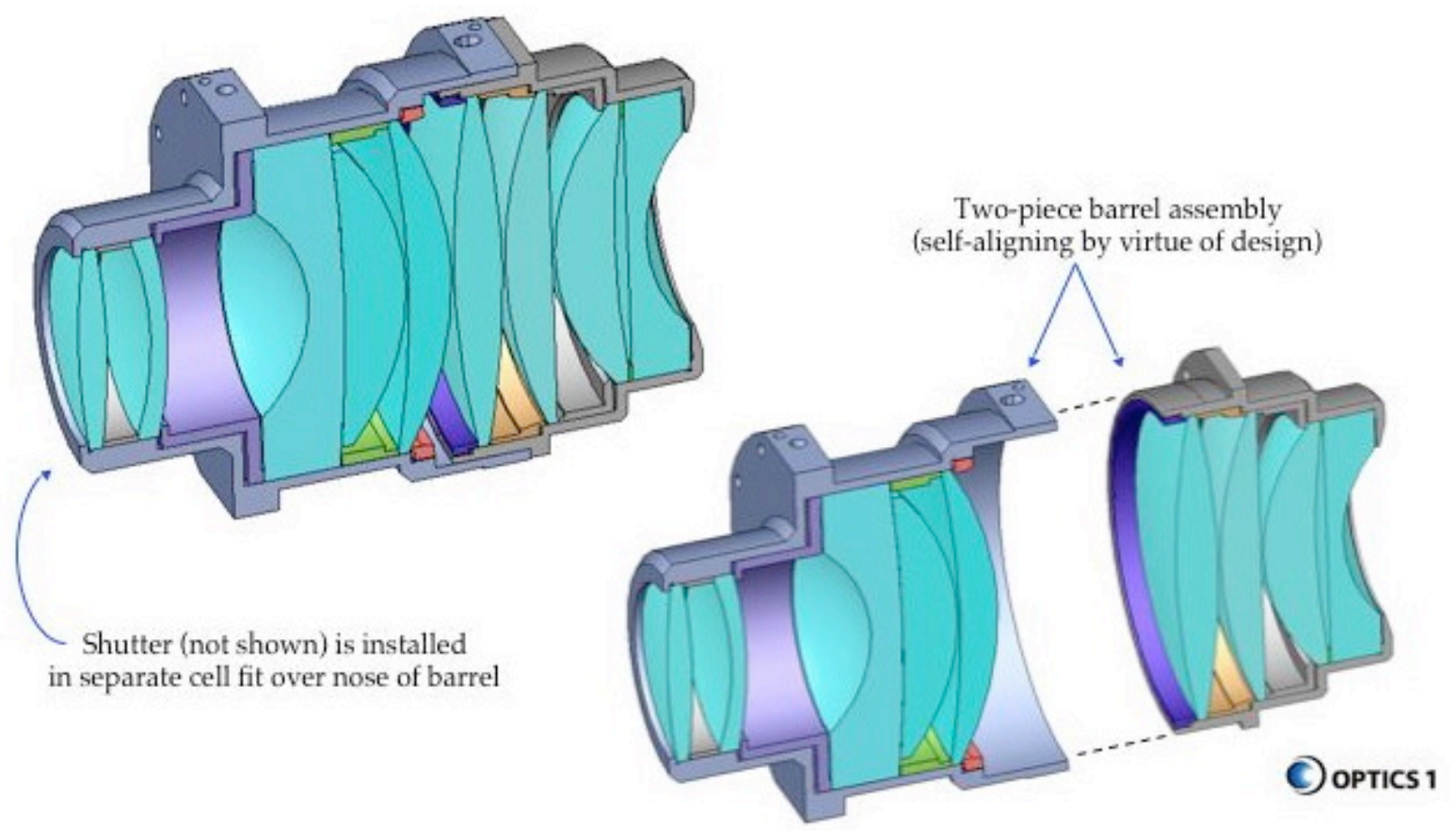

Figure 14: Cutaway drawing of lens assembly built by Optics1. This is a 9-element lens which has been designed to provide high light collection efficiency $(\approx f / 1.25)$ and uniform focus over the full $65 \mathrm{~cm} \mathrm{X} 65 \mathrm{~cm}$ field of view at the scintillator. A high-speed electronic shutter will also be provided by Optics1 to prevent stray light from entering the lens between image frames.
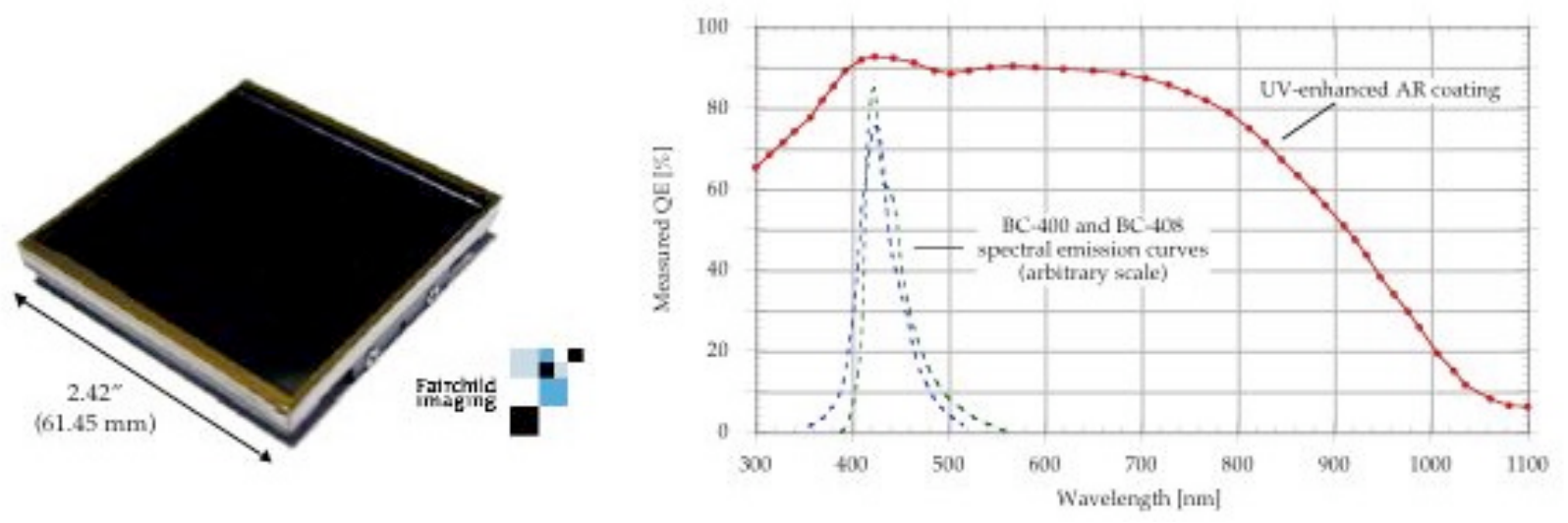

Figure 15: Fairchild 4096 X 4096, $15 \mu \mathrm{m}$ pixel, back-illuminated imaging sensor and associated quantum efficiency curve. The "UV-enhanced" anti-reflective coating on this large-format chip has been optimized for BC-400/BC-408 spectral sensitivity. 